\title{
The human epidermis
}

\author{
BY KARIN U. SCHALLREUTER \\ Department of Dermatology, University of Hamburg, Hamburg, Germany \\ AND JOHN M. WOOD \\ Department of Biomedical Sciences, University of Bradford, Bradford BD7 1DP
}

The human skin represents the largest organ in the human body with an average surface area of $1.8 \mathrm{~m}^{2}$, where the epidermis is the outermost living layer. Keratinocytes and melanocytes, in the ratio 36:1, form the epidermal unit. A symbiotic relationship exists between these cells with regard to the processes of signal transduction, metabolism, cell growth, differentiation and defence against damaging oxygen radicals (ROS). Recent results suggest that the epidermis has a metabolic similarity to neuronal tissue, with the capacity to synthesize as well as degrade catecholamines (Schallreuter et al. 1992, 1994d). In association with catecholamine synthesis, there is expression of a high density of $\beta$-2-adrenoceptors on keratinocytes and $\alpha$-adrenoceptors on melanocytes (Steinkraus et al. 1991, 1992; Schallreuter et al. 1993). Since undifferentiated keratinocytes (i.e. basal cells) provide the major supply of catecholamines to the total epidermis, it seems feasible that those basal cells in contact with melanocytes are of major importance in signal transduction, metabolism, growth and differentiation. Any local trauma to the epidermis by infection or physical damage can attract infiltrating lymphocytes to produce the biological 'oxygen-burst' leading to a local release of superoxide anion radicals $\left(\mathrm{O}_{2}^{-}\right)$at high concentration via the activity of NADPH-oxidase ( $E C$ 1.6.2.2). In addition, radicals can be produced by u.v. light and other environmental factors. Consequently, the epidermis invests a significant amount of metabolic energy in neutralizing ROS such as $\mathrm{O}_{2}^{-}, \mathrm{H}_{2} \mathrm{O}_{2}$ and $\mathrm{OH} \bullet$ (Schallreuter \& Wood, 1989).

\section{NUTRIENT SUPPLY}

The epidermis is unique compared with other organs in that there is no direct vascular supply. The availability of essential nutrients, minerals and molecular oxygen occurs via diffusion and transport from the dermal compartment across the basal membrane and into the interstitial spaces between keratinocytes and melanocytes. Keratinocytes must have a constant supply of nutrients, essential amino acids, vitamins, minerals, etc., because these cells have a turnover of approximately $10 \mathrm{~d}$, yielding the impermeable stratum corneum. However, this stratum corneum maintains an efficient barrier function. As a consequence, keratinocytes undergo a cycle of programmed cell death, with rapid metabolism, growth and efficient differentiation representing major processes in their short life-span. The pigment-producing cells, the melanocytes, are also very specialized, with the formation of black eumelanin and red pheomelanin. These cells are responsible for the constitutive skin colour. In addition, the melanins with their complex highmolecular-weight polymers are important primarily in defence against ROS, and also offer some u.v. absorption properties (Prota, 1992). 


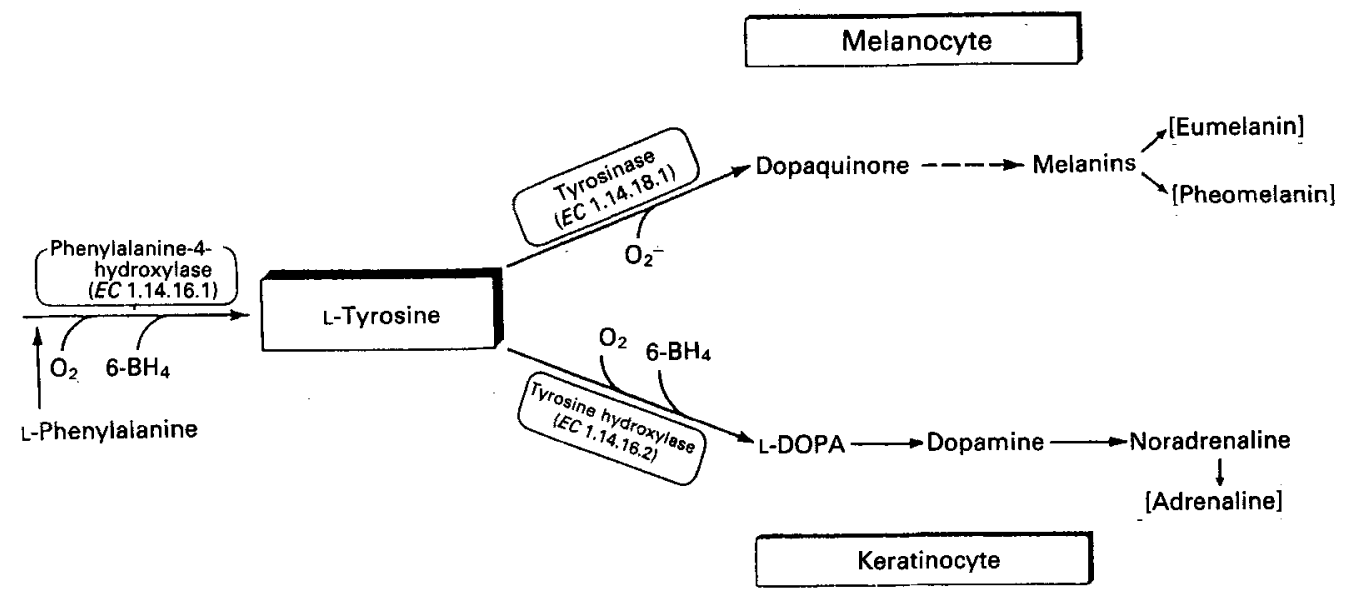

Fig. 1. Branched metabolic pathway for the biosynthesis of catecholamines by keratinocytes and the melanins by melanocytes. The supply of L-tyrosine from L-phenylalanine in the epidermis controls both processes. 6- $\mathrm{BH}_{4}, 5,6,7,8$-tetrahydrobiopterin; L-DOPA, L-3,4-dihydroxyphenylalanine.

The integrity of the epidermis is extremely dependent on Ca homeostasis. This fast-exchange ion is important to signal transduction, cell differentiation and in the regulation of keratinization and melanogenesis. A Ca gradient has been described, with low concentrations in basal cells and highest concentrations in the outermost living epidermal layer (Menon et al. 1985).

\section{SIGNAL TRANSDUCTION AND THE CONTROL OF THE KERATINOCYTE LIFE-CYCLE}

Both keratinocytes and melanocytes have the capacity to express various c-AMPdependent and -independent signal-transduction systems. However, the biosynthesis of the catecholamines by keratinocytes highlights the importance of the availability of the essential amino acid L-phenylalanine as a major key in the control of keratinocyte differentiation, as well as for melanogenesis by melanocytes. Fig. 1 presents the central position of L-phenylalanine in the biosynthesis of the catecholamines in keratinocytes and the melanins by melanocytes.

It has been shown that the biosynthesis of L-tyrosine from L-phenylalanine occurs in the cytosol of keratinocytes and melanocytes (Schallreuter et al. 1994b). This step is controlled by the activity of phenylalanine-4-hydroxylase (EC 1.14.16.1; PAH). The enzyme is regulated by the supply of the essential cofactor-two electron donor (6R) 5,6,7,8-tetrahydrobiopterin $\left(6-\mathrm{BH}_{4}\right.$; the stereochemistry is the $6 \mathrm{R}$ configuration with $6 \mathrm{~S}$ being inactive as a cofactor). Both keratinocytes and melanocytes contain the complete pathways for the de novo synthesis of $6-\mathrm{BH}_{4}$ and for its recycling. The rate-limiting enzyme for the de novo synthesis of 6-BH $\mathrm{BH}_{4}$ is GTP-cyclohydrolase $\mathrm{I}$ ( $E C$ 3.5.4.16), whereas the recycling depends on 4a-hydroxy-6- $\mathrm{BH}_{4}$ dehydratase ( $E C$ 3.4.5.10; DH). Fig. 2 presents the central position of $6-\mathrm{BH}_{4}$ in control of $\mathrm{PAH}$. 


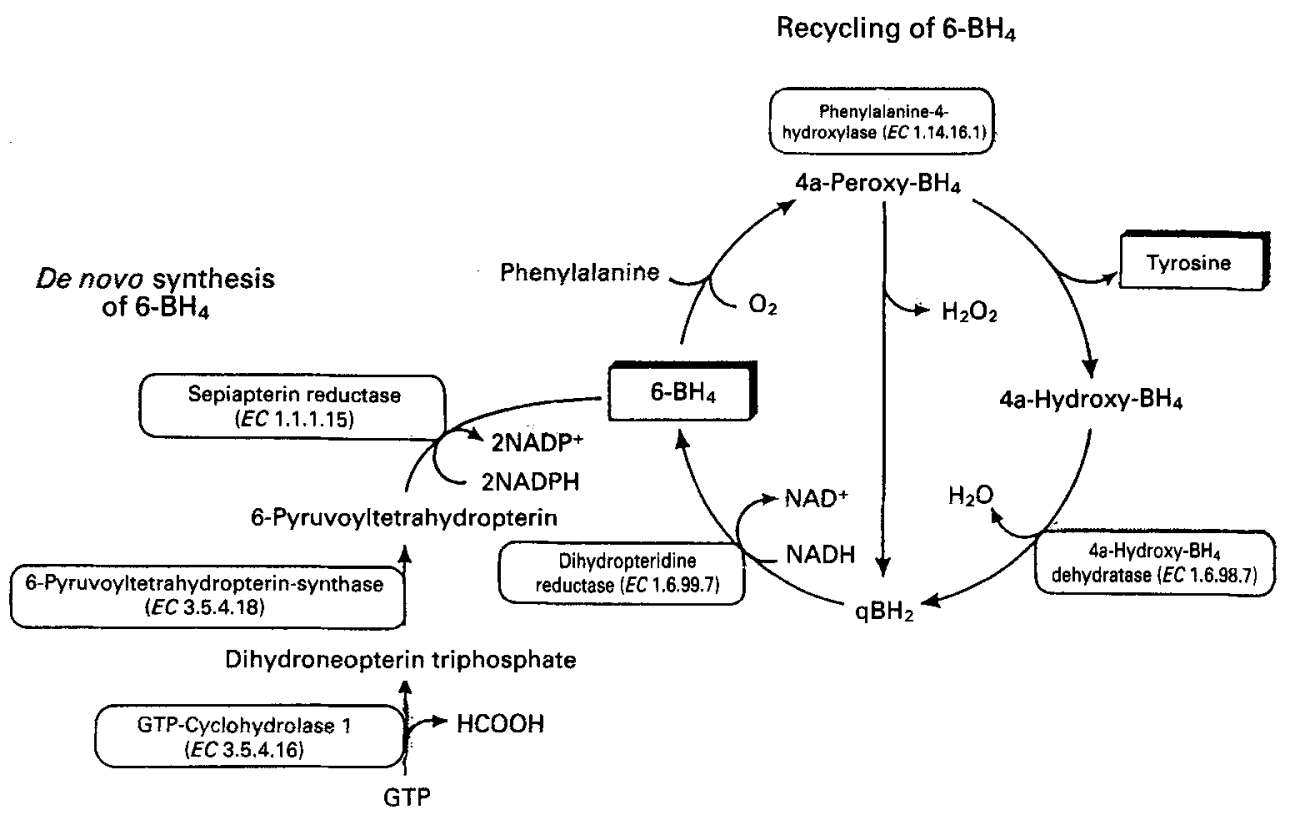

Fig. 2. The de novo synthesis and recycling of $(6 \mathrm{R}) 5,6,7,8$-tetrahydrobiopterin. 6-BH 4 , 5,6,7,8-tetrahydrobiopterin; $\mathrm{qBH}_{2}$, dihydrobiopterin (quinonoid).

Recently DH has been shown to possess a dual function as:

(a) rate-limiting catalyst in the recycling of $6-\mathrm{BH}_{4}$, and

(b) as the activator-dimerization factor for hepatocyte nuclear factor I

(HNF-I; Citron et al. 1992; Hauer et al. 1993).

HNF-I has been shown to function as a homodimer-transcription factor recognizing a sixteen-base inverted palindrome in the promoter regions of eleven genes in the liver. Based on the analysis of twenty-six genes, a consensus sequence for this important regulatory binding site has been established (Mendel \& Crabtree, 1991). A computer analysis of the gene controlling the key enzyme for melanogenesis as well as the genes for the synthesis of dopamine, norepinephrine and epinephrine yielded putative binding sequences for the HNF-I homodimer in their promoter regions. For human tyrosinase (EC 1.14.18.1), 2,3,-dihydroxyphenylalanine (DOPA) decarboxylase ( $E C 4.1 .1 .26)$ and phenylethanolamine-N-methyltransferase (EC 2.1.1.28), the HNF-I binding domain is located close enough to the TATA start code to function as a direct regulator of gene transcription. For dopamine hydroxylase ( $E C$ 1.14.17.1), the putative HNF-I binding site is too far away from the TATA box for direct control of transcription, but it may function as an enhancer in the control of dopamine hydroxylase m-RNA synthesis.

Human tyrosinase has $81 \%$ sequence homology to the HNF-I concensus sequence, DOPA dehydroxylase has $87 \%$ homology, dopamine hydroxylase $75 \%$ homology and phenylethanolamine-N-methyltransferase $69 \%$ homology. Based on these new observations, it appears that DH plays an important role in the control of both the supply of L-tyrosine and regulation of m-RNA synthesis for the key enzyme tyrosinase in melanocytes, and for the catecholamines in keratinocytes (B. Nye, N. J. Lindsey, J. M. Wood and K. U. Schallreuter, unpublished results). 
The synthesis of the catecholamines by keratinocytes is closely associated with the expression of $\beta$-2-adrenoceptors on these cells as well as the $\alpha$-adrenoceptor expression on melanocytes (Schallreuter, 1993; Schallreuter et al. 1994d). Concomitant with the expression of $\beta$-2-adrenoceptors on keratinocytes, there is a rapid influx of Ca from the extracellular matrix controlling the differentiation process (Schallreuter et al. 1994a). The $\beta$-2-adrenoceptor signal-transduction system in keratinocytes apparently controls $\mathrm{Ca}$ homeostasis which, in turn, influences the life-cycle of these short-lived cells. Melanocytes express $\alpha$-adrenoceptors only. However, at the present time, this expression and regulation is not fully understood.

\section{DEFENCE AGAINST OXYGEN RADICALS IN THE EPIDERMAL UNIT}

An examination of the cytosol fraction from epidermal tissue by FPLC reveals the presence of high levels of antioxidant enzymes such as catalase $(E C 1.11 .1 .6$; CAT) and the thioproteins glutathione reductase $(E C$ 1.6.4.2; GR) and thioredoxin reductase $(E C$ 1.6.4.5; TR). On the other hand, the concentration of superoxide dismutase ( $E C$ 1.15.1.1; SOD) is relatively low by comparison with other organs such as liver and kidney (Carraro \& Pathak, 1988). Furthermore, epidermal immuno-staining with monoclonal antibody shows that SOD is present mostly in the basal keratinocytes. The presence of SOD in the epidermis, leading to the formation of $\mathrm{H}_{2} \mathrm{O}_{2}$ from $\mathrm{O}_{2}^{-}$radicals, could be damaging to the generation of hydroxyl radicals $(\mathrm{OH} \bullet)$ from $\mathrm{H}_{2} \mathrm{O}_{2}$ via the Haber-Weiss reaction (Schallreuter et al. 1991). Hence, the epidermis primarily relies on alternative mechanisms. Keratinocytes primarily express both plasma-membrane-associated and cytosolic TR and its natural electron acceptor-substrate thioredoxin (T) for an effective removal of $\mathrm{O}_{2}^{-}$(Schallreuter \& Wood, 1989). Recent findings reported by Yodoi \& Uchiyama (1992) and Schallreuter et al. (1994c) have shown that both TR and T are induced by $\mathrm{O}_{2}^{-}$radicals; meanwhile, the levels of CAT and GR are decreased under these conditions due to inactivation by increased ROS in the epidermis. In addition, both the TR-T system as well as tyrosinase represent effective trapping mechanisms for $\mathrm{O}_{2}{ }^{-}$ to defend melanocytes against the cytotoxicity of ROS.

\section{CONCLUDING REMARKS}

Since the epidermis has no vascular supply, it receives all its nutrients, vitamins and minerals either by diffusion or by transport across the basal membrane into intracellular matrices between the keratinocytes and melanocytes. The high metabolic activity of basal cells in the healthy epidermis requires efficient active transport together with a responsive signal-transduction network. For example, in the epidermis, the adrenergic signal controls $\mathrm{Ca}$ homeostasis and this fast-exchange ion regulates metabolism, growth and cell differentiation.

\section{REFERENCES}

Carraro, C. \& Pathak, M. A. (1988). Characterization of superoxide dismutase from mammalian skin epidermis. Journal of Investigative Dermatology 90, 31-36.

Citron, B. A., Davis, M. D., Milstein, S., Gutierrez, J., Mendel, D. B., Crabtree, G. R. \& Kaufman, S. (1992). Identity of 4a-carbinolamine dehydratase, a component of the phenylalanine hydroxylase system, and DCoH, a transregulator of homeodomain proteins. Proceedings of the National Academy of Sciences, USA 89, 11891-11894. 
Hauer, C. R., Rebrin, I., Thony, B., Neuhieser, F., Curtius, H. C., Henziker, Pl., Blau, N., Ghisla, S. \& Heizmann, C. W. (1993). Phenylalanine hydroxylase-stimulating pterin/pterin-4a-carbinolamine dehydratase from rat and human liver. Journal of Biological Chemistry 268, 4828-4831.

Mendel, D. B. \& Crabtree, G. R. (1991). HNF-1, a member of a novel class of dimerizing homeodomain proteins. Journal of Biological Chemistry 266, 677-680.

Menon, G. K., Grayson, S. \& Elias, P. (1993). Ionic calcium reservoirs in mammalian epidermis, ultrastructural analysis by ion capture cytochemistry. Journal of Investigative Dermatology 84, 508-512.

Prota, G. (1992). Melanins and Melanogenesis. New York: Academic Press.

Schallreuter, K. U. (1994). New aspects in the pathophysiology of vitiligo. Current Opinion in Dermatology, 256-261.

Schallreuter, K. U., Lemke, K. R., Pittelkow, M. R., Wood, J. M., Körner, C. \& Malik, R. (1994a). Catecholamines in human keratinocyte differentiation. Journal of Investigative Dermatology (In the Press).

Schallreuter, K. U., Lemke, K. R., Wood, J. M. \& Hill, H. Z. (1994b). Thioredoxin reductase induction coincides with melanin biosynthesis in brown and black guinea pigs. Journal of Investigative Dermatology 103, 820-824.

Schallreuter, K. U. \& Wood, J. M. (1989). Free radical defense at the surface of the human skin. Free Radicals in Biology and Medicine 6, 519-532.

Schallreuter, K. U., Wood, J. M. \& Berger, J. (1991). Low catalase levels in the epidermis of patients with vitiligo. Journal of Investigative Dermatology 97, 1081-1085.

Schallreuter, K. U., Wood, J. M., Lemke, R., LePoole, C., Das, P., Westerhof, W., Pittelkow, M. R. \& Thody, A. J. (1992). Production of catecholamines in the human epidermis. Biochemical and Biophysical Research Communications 189, 72-78.

Schallreuter, K. U., Wood, J. M., Pittelkow, M. R., Gütlich, M., Lemke, R., Rödl, W., Swanson, N. N., Hitzemann, K. \& Ziegler, I. (1994c). Regulation of melanin biosynthesis in the human epidermis by tetrahydrobiopterin. Science 263, 1444-1446.

Schallreuter, K. U., Wood, J. M., Pittelkow, M. R., Swanson, N. N. \& Steinkraus, V. (1993). Increased in vitro expression of beta-2-adrenoceptors in differentiating lesional keratinocytes of vitiligo patients. Archives of Dermatological Research 285, 216-220.

Schallreuter, K. U., Wood, J. M., Ziegler, I., Lemke, K. R., Pittelkow, M. R., Lindsey, N. J. \& Gütlich, M. (1994d). Defective tetrahydrobiopterin and catecholamine biosynthesis in the depigmentation disorder vitiligo. Biochimica et Biophysica Acta 1226, 181-192.

Steinkraus, V., Körner, C. \& Steinfath, M. (1991). High density of beta-2-adrenoceptors in a human keratinocyte cell line with complete epidermal differentiation capacity (HaCat). Archives of Dermatological Research 283, 328-332.

Steinkraus, V., Steinfath, M. \& Körner, C. (1992). Binding of beta-2-adrenergic receptors in human skin. Journal of Investigative Dermatology 98, 475-480.

Yodoi, J. \& Uchiyama, T. (1992). Diseases associated with HTCV-1 virus, IL-2 receptor dysregulation and redox regulation. Immunology Today 13, 405-411. 